\title{
Cytotoxicity of Carbon Nanotubes on J774 Macrophages Is a Purification-Dependent Effect
}

\author{
Silvia Lorena Montes-Fonseca, ${ }^{1}$ Erasmo Orrantia-Borunda, ${ }^{1}$ \\ Alberto Duarte-Möller, ${ }^{1}$ Antonia Luna-Velasco, ${ }^{1}$ Manuel Román-Aguirre, ${ }^{1}$ \\ Carmen González Horta, ${ }^{2}$ and Blanca Sánchez-Ramírez ${ }^{2}$ \\ ${ }^{1}$ Departamento de Energías Renovables y Protección al Medio Ambiente, Centro de Investigación en Materiales Avanzados (CIMAV), \\ Miguel de Cervantes 120, Complejo Industrial Chihuahua, 31109 Chihuahua, CHIH, Mexico \\ ${ }^{2}$ Departamento de Biotecnología, Facultad de Ciencias Químicas, Universidad Autónoma de Chihuahua, \\ 31125 Chihuahua, CHIH, Mexico
}

Correspondence should be addressed to Erasmo Orrantia-Borunda, erasmo.orrantia@cimav.edu.mx

Received 16 February 2012; Revised 3 May 2012; Accepted 8 May 2012

Academic Editor: Krasimir Vasilev

Copyright (C) 2012 Silvia Lorena Montes-Fonseca et al. This is an open access article distributed under the Creative Commons Attribution License, which permits unrestricted use, distribution, and reproduction in any medium, provided the original work is properly cited.

The cytotoxicity of the carbon nanotubes (CNTs) is an important factor for the manufacture of nanovaccines. The aim of this work was to evaluate the relationship of the purification method of CNTs in cellular toxicity using macrophages (MOs) from the J774 cell line. Viability test was performed with MTT assays at $24 \mathrm{~h}$ of exposure at concentrations of $0.06,0.6$, and $6 \mathrm{mg} / \mathrm{L}$ of unpurified (UP-CNTs) or purified (P-CNTs) CNTs by two different methods: (1) reflux with $3 \mathrm{M} \mathrm{HNO}_{3}$ and (2) sonication in $\mathrm{H}_{2} \mathrm{SO}_{4} / \mathrm{HNO}_{3}$. Characterization and $\mathrm{COOH}$ content of $\mathrm{CNTs}$ was performed using scanning electron microscopy, raman spectroscopy, and titration with $\mathrm{NaHCO}_{3}$. P-CNTs 1 had lengths $>100 \mu \mathrm{m}$ and $2.76 \% \mathrm{COOH}$ content, while P-CNTs $s_{2}$ had lengths $>1 \mu \mathrm{m}$ and $7 \%$ $\mathrm{COOH}$ content. This last particle showed a lower toxic effect. The results suggest that the lenght and $\mathrm{COOH}$ content are important factors in the toxicity of the CNTs.

\section{Introduction}

Carbon nanotubes (CNTs) are cylindrical nanoparticles, which have unique structure and fascinating physical and chemical properties allowing them to be used in biotechnological applications $[1,2]$. Due to their ability to penetrate plasmatic membrane [3], CNTs may be used as particulate substances carriers in biological systems $[4,5]$, as well as in biosensors to detect cellular tumors [6], and for nanovaccine production $[7,8]$. Nevertheless, these applications are limited by the high insolubility of CNTs, which conduct to generate CNTs deposition in cells, organs, and tissues, causing toxic effects [9]. Several studies have demonstrated that CNTs provoke cellular apoptosis and a decrease in viability in lung tumor cells [10], human fibroblasts [11], human T lymphocytes [12], and umbilical vein endothelial cells [13]. It has also been observed that CNTs induce the production of reactive oxygen species in human epidermal keratinocytes
(HEKs) [14] and macrophages cells [15, 16]. Some authors attribute these effects to the hydrophobic nature of the CNTs, fabrication residues, and high surface area and size [17]. According to this last point, many authors converge with the notion that the length of CNTs is an additional factor for cellular toxicity. Poland et al. [18] found that intraperitoneal exposure of mice to multiwall CNTs with length of $20 \mu \mathrm{m}$ or longer resulted in asbestosis-like pathology.

Some authors recommend to purify the CNTs previous to test in a biological system, in order to eliminate the fabrication residues. Saito et al. [19] performed a purification technique using a mixture of concentrated $\mathrm{H}_{2} \mathrm{SO}_{4} / \mathrm{HNO}_{3}$ $3: 1 \mathrm{v} / \mathrm{v}$ and sonication in a water bath for $22 \mathrm{~h}$. They obtained shortened CNTs with length $<1 \mu \mathrm{m}$ and found that these can be easily dispersed in polar solvents such as ethanol, dimethyl sulfoxide, and dimethyl formamide. In addition, acid-treated CNTs are excellent candidates for functionalization with amino compounds [19] to be used in 
biomedical applications. However, studies about toxicity of these particles in biological systems have not been done. Therefore, the aim of this work was to evaluate the relationship of the purification method of CNTs in cellular toxicity using macrophages (MOs) from the J774 cell line.

\section{Methods}

2.1. Synthesis and Purification of CNTs. CNTs were synthesized by spray pyrolysis, using toluene and ferrocene as the carbon source and the catalyst, respectively [20]. For the first group of CNTs $\left(\mathrm{CNTs}_{1}\right)$ the synthesis time was $20 \mathrm{~min}$ and the purification was carried out with $0.1 \mathrm{~g}$ of unpurified CNTs (UP-CNTs ${ }_{1}$ ) and $150 \mathrm{~mL}$ of $\mathrm{HNO}_{3} 3 \mathrm{M}$. The mixture was dispersed by sonication for $90 \mathrm{~min}$ and refluxed for $24 \mathrm{~h}$. Purified CNTs of the first group ( $\left.\mathrm{P}-\mathrm{CNTs}_{1}\right)$ were filtered and washed with distilled water in an oven at $90^{\circ} \mathrm{C}$ for $8 \mathrm{~h}$. For the second group of CNTs $\left(\mathrm{CNTs}_{2}\right)$ the synthesis time was $2 \mathrm{~min}$ and the purification method was as follows: $0.2 \mathrm{~g}$ of UP-CNTs 2 was suspended in $400 \mathrm{~mL}$ of a mixture of concentrated $\mathrm{H}_{2} \mathrm{SO}_{4}(90 \%) / \mathrm{HNO}_{3}(70 \%) 3: 1 \mathrm{v} / \mathrm{v}$ and sonicated in a water bath for $48 \mathrm{~h}$. The resultant P-CNTs 2 were collected with a polytetrafluoroenthylene filter with $450 \mathrm{~nm}$ pore size and washed four times with water and methanol, respectively. Finally, the $\mathrm{P}_{-} \mathrm{CNTs}_{2}$ were dried at room temperature [19].

2.2. Characterization of CNTs. The CNTs were characterized by scanning electronic microscopy (SEM) in a JEOL SEM, model JSM-5800 LV equipped with an energy dispersive $\mathrm{X}$-ray analyzer (for elemental analysis). The quality of the structure of CNTs was measured by Raman spectroscopy using a micro-Raman LabRAM HR, Horiba Jobn Yvon, coupled to Olympus BX-4 microscope. The laser line used to excite the sample was $632.8 \mathrm{~nm}$ and all measurements were performed at room temperature. The carboxyl groups $(\mathrm{COOH})$ in the P-CNTs were measured by titration with $\mathrm{NaHCO}_{3}$ base on a method established by $\mathrm{Hu}$ et al. [21], modified as follows: $0.1 \mathrm{~g}$ of P-NTC 1 and P-NTC 2 was stirred in $50 \mathrm{~mL}$ of $0.05 \mathrm{~N} \mathrm{NaHCO}_{3}$ aqueous solution. The mixture was then filtered through a membrane (pore size of $0.45 \mu \mathrm{m}$ ). The P-NTCs collected on the membrane were washed with deionized water to remove the $\mathrm{NaHCO}_{3}$ residues. The combined filtrate and washings were added to $50 \mathrm{~mL}$ of $0.05 \mathrm{~N}$ aqueous $\mathrm{HCl}$ solution and boiled for $20 \mathrm{~min}$ to degas the $\mathrm{CO}_{2}$ of the solution. After cooling to room temperature, the excess $\mathrm{HCl}$ in the solution was titrated with $0.05 \mathrm{~N}$ aqueous $\mathrm{NaOH}$ solution to reach a neutral $\mathrm{pH} 7.00$ [21].

2.3. Viability Tests in J774 MOs Cell Line. Cell viability was determined using 3-(4,5-dimethylthiozol-2-yl)-2,5-diphenyltetrazolium bromide (MTT) assays (Sigma, St. Louis MI, USA) in 96-well plates, as described previously [22]. Briefly, $10^{5}$ cells were cultivated in DMEM-HG supplemented with $10 \%$ heat-inactivated bovine fetal serum, $100 \mathrm{IU} / \mathrm{mL}$ of penicillin, $100 \mu \mathrm{m} / \mathrm{mL}$ of streptomycin, and $2 \mathrm{mM} \mathrm{L}$-glutamine; MOs were interacted with UP-CNTs $s_{1}, \mathrm{P}-\mathrm{CNTs}_{1}, \mathrm{UP}-\mathrm{CNTs}_{2}$, and $\mathrm{P}-\mathrm{CNTs}_{2}$ in supplemented DMEM-HG at concentrations of $0.06,0.6$, and $6 \mathrm{mg} / \mathrm{L}$ and sonicated for $30 \mathrm{~min}$
TABLE 1: Analysis of elements found in unpurified (UP) or purified (P) samples of $\mathrm{CNT}_{1}$ and $\mathrm{CNT}_{2}$.

\begin{tabular}{lcccc}
\hline & \multicolumn{2}{c}{$\mathrm{CNTs}_{1}$ \% weight* } & \multicolumn{2}{c}{$\mathrm{CNTs}_{2}$ \% weight* } \\
Element & $\mathrm{UP}^{*} \mathrm{CNTs}_{1}$ & $\mathrm{P}^{*} \mathrm{CNTs}_{1}$ & $\mathrm{UP}-\mathrm{CNTs}_{2}$ & $\mathrm{P}-\mathrm{CNTs}_{2}$ \\
\hline $\mathrm{C}$ & 94.83 & 93.23 & 95.56 & 75.98 \\
$\mathrm{O}$ & 1.26 & 4.26 & 1.22 & 22.21 \\
$\mathrm{Fe}$ & 3.89 & 1.12 & 3.23 & 1.81 \\
\hline Total & 100 & 100 & 100 & 100 \\
\hline * Element
\end{tabular}

Element content was determined by semiquantitative analysis of elemental composition.

previous to cell interaction. Cultures were incubated for $24 \mathrm{~h}$ at $37^{\circ} \mathrm{C}$ in humid atmosphere at $5 \% \mathrm{CO}_{2}$. MOs without stimulus were used as control. At $20 \mathrm{~h}$ of cultivation time, $0.1 \mathrm{mg}$ of MTT dissolved in sterile phosphate-buffered saline was added to each well and incubated for $4 \mathrm{~h}$ more. Cells were lyzed with acidified isopropanol and absorbances at $590 \mathrm{~nm}$ were quantified using a BioRad ELISA microreader.

2.4. Statistical Analysis. Statistical analysis was carried out through the Minitab software and using a one-way ANOVA in order to determine the difference between the MOs interactions with different CNTs at all the concentrations used.

\section{Results and Discussion}

3.1. Characterization of CNTs. The different groups of CNTs were characterized by SEM (Figure 1). The dimensions obtained for UP-CNTs 1 averaged 20 to $100 \mathrm{~nm}$ in diameter and $120 \mu \mathrm{m}$ in length (Figures $1(\mathrm{a})$ and $1(\mathrm{c})$ ). The P-CNTs 1 obtained by reflux with $\mathrm{HNO}_{3} 3 \mathrm{M}$ showed better particle dispersion than UP-CNTs $s_{1}$. Also open-end formations were favored in P-CNTs 1 , but length was similar than for UP$\mathrm{CNTs}_{1}$. Semiquantitative analysis of elemental composition (Table 1) showed a $2.77 \%$ decrease in Fe content between unpurified and purified samples, as well a slight increase in $\mathrm{O}$ content from 1.26 to $4.26 \%$. On other hand, the dimensions for UP-CNTs $s_{2}$ averaged $20-40 \mathrm{~nm}$ in diameter and $30 \mu \mathrm{m}$ in length (Figures $1(\mathrm{~b})$ and $1(\mathrm{~d})$ ). $\mathrm{P}-\mathrm{CNTs}_{2}$ obtained by sonication with $\mathrm{H}_{2} \mathrm{SO}_{4} / \mathrm{HNO}_{3} 3: 1 \mathrm{v} / \mathrm{v}$ showed a considerable decrease of their length from $30 \mu \mathrm{m}$ to $<1 \mu \mathrm{m}$ (Figure 1(f)). Likewise, the semiquantitative analysis of elemental composition showed a $1.42 \%$ decrease in Fe content and an increase in O content from 1.22 to $22.21 \%$, in P-CNTs 2 (Table 1).

These results indicates that both purification techniques encourage to an effective removal of Fe from the surface of the UP-CNTs. However, the length and the $\mathrm{O}$ content are quite different between $\mathrm{P}-\mathrm{CNTs}_{1}$ and $\mathrm{P}-\mathrm{CNTs}_{2}$. Although P$\mathrm{CNTs}_{1}$ showed an increase in $\mathrm{O}$ content, $\mathrm{P}-\mathrm{CNTs}_{2}$ had an increase of fivefold, indicating a greater addition of oxidized groups $(\mathrm{COOH}, \mathrm{OH}, \mathrm{CO})$ on the surface of the CNTs [19, 23].

In order to confirm that the $\mathrm{O}$ content on the surface of the P-CNTs was related with the addition of $\mathrm{COOH}$ groups, these last were measured by tritration with $\mathrm{NaHCO}_{3}$ as was indicated in the methodology section. The tritration results clearly showed that $\mathrm{P}_{-} \mathrm{CNTs}_{2}$ had a higher percentage of 


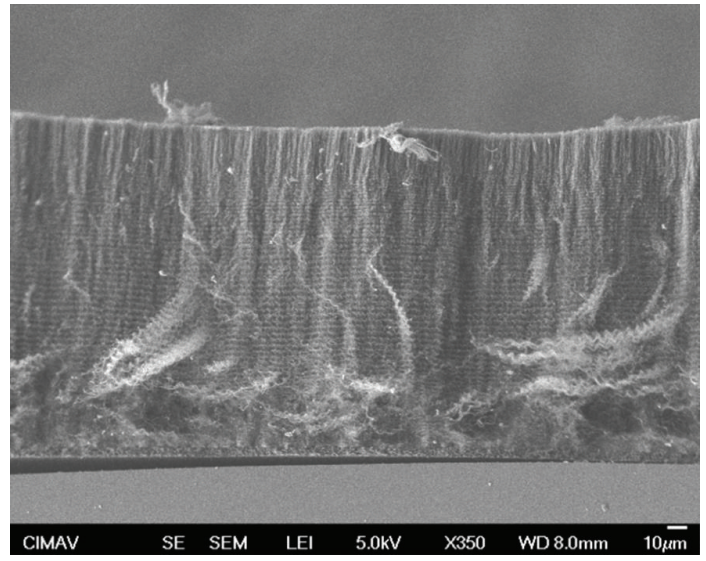

(a)

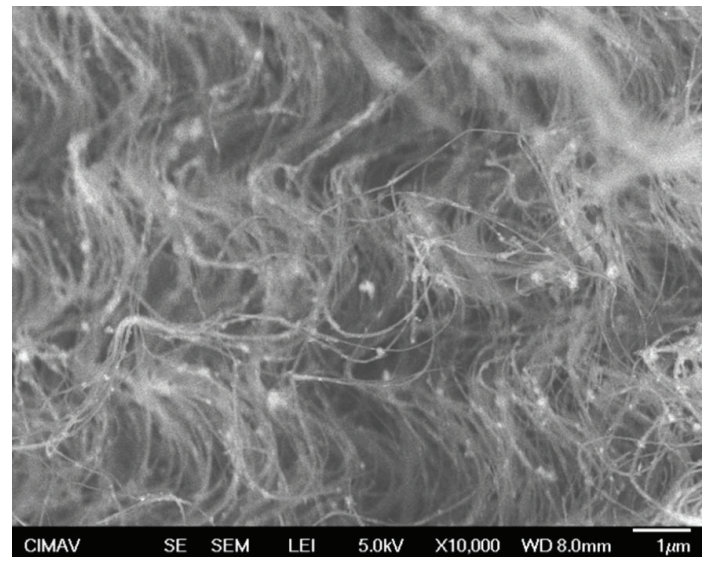

(c)

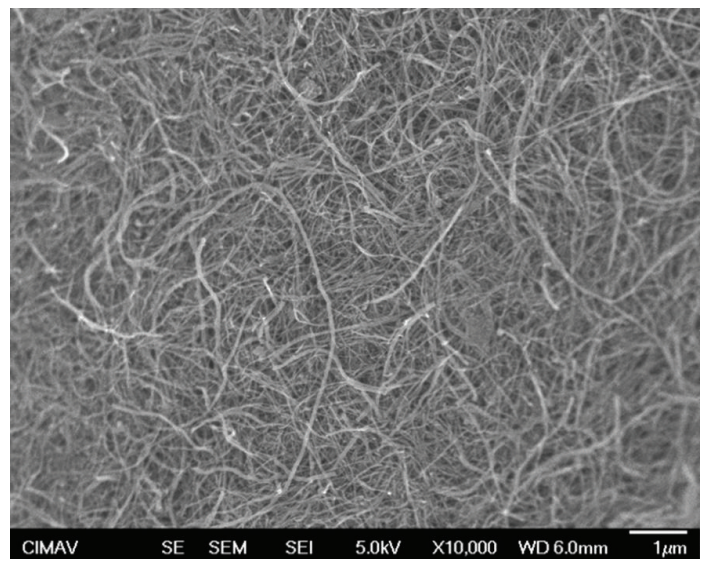

(e)

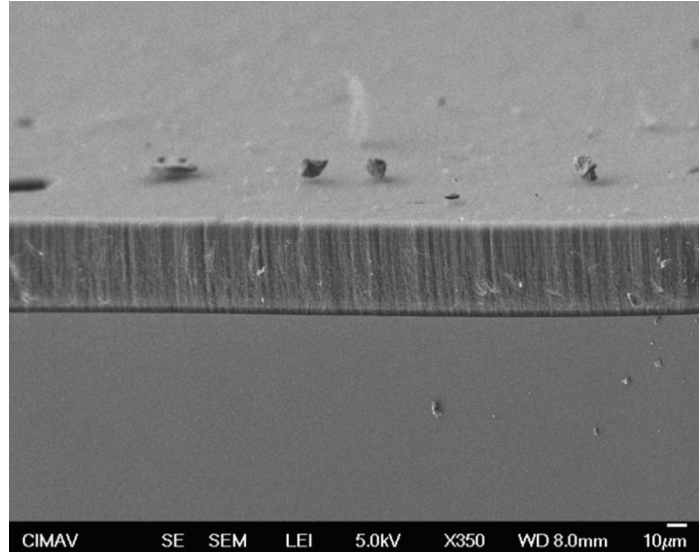

(b)

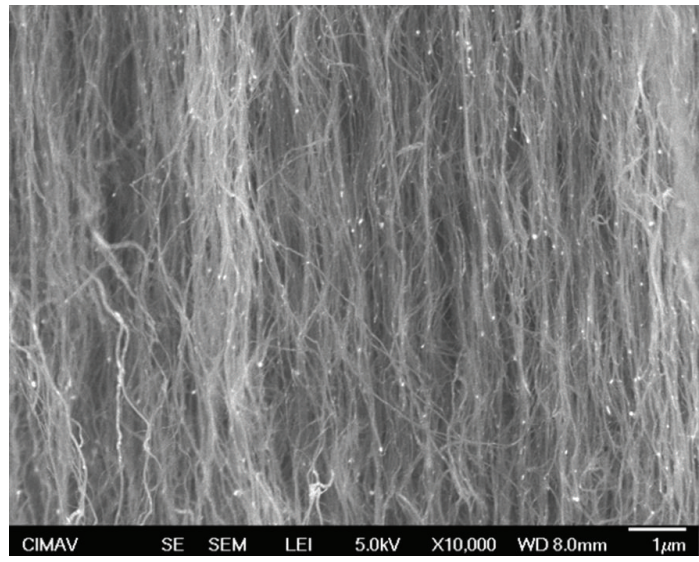

(d)

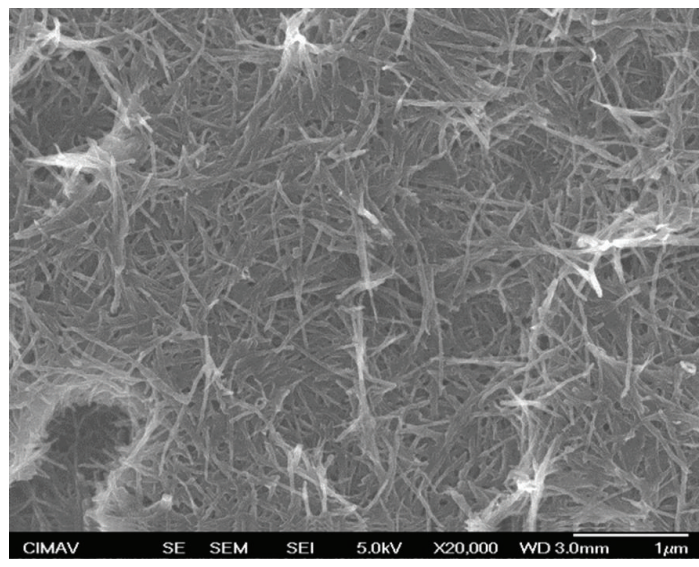

(f)

Figure 1: Photomicrophotographs of UP-CNTs and P-CNTs obtained by SEM. Microphotographs show length for UP-CNTs ${ }_{1}$ and UP$\mathrm{CNTs}_{2}$ ((a), (b) resp.) and diameter for UP-CNTs ${ }_{1}$ and UP-CNTs 2 ((c), (d) resp.). (e) and (f) are shown characteristics of P-CNTs 1 and $\mathrm{P}-\mathrm{CNTs}_{2}$ respectively.

COOH groups (7\%) than in $\mathrm{P}-\mathrm{CNTs}_{1}(2.76 \%)$. This indicates that the acid purification process combined with sonication (used for $\mathrm{P}-\mathrm{CNTs}_{2}$ ) increased the formation of acid groups on the surface of P-CNTs due to the strong interaction of CNTs allowing open-end formations and promoting the oxidation of exposed carbon atoms [24].
On the other hand, the quality of the CNTs structures was determined by Raman spectroscopy. Figure 2 shows the raman spectra for $\mathrm{UP}_{-} \mathrm{CNTs}_{1}, \mathrm{UP}-\mathrm{CNTs}_{2}, \mathrm{P}-\mathrm{CNTs}_{1}$, and P$\mathrm{CNTs}_{2}$. Each of them consists of two characteristic bands, namely, D-band at $1338 \mathrm{~cm}^{-1}$ and G-band at $1600 \mathrm{~cm}^{-1}$. The G-band is a characteristic feature of the graphitic layers 


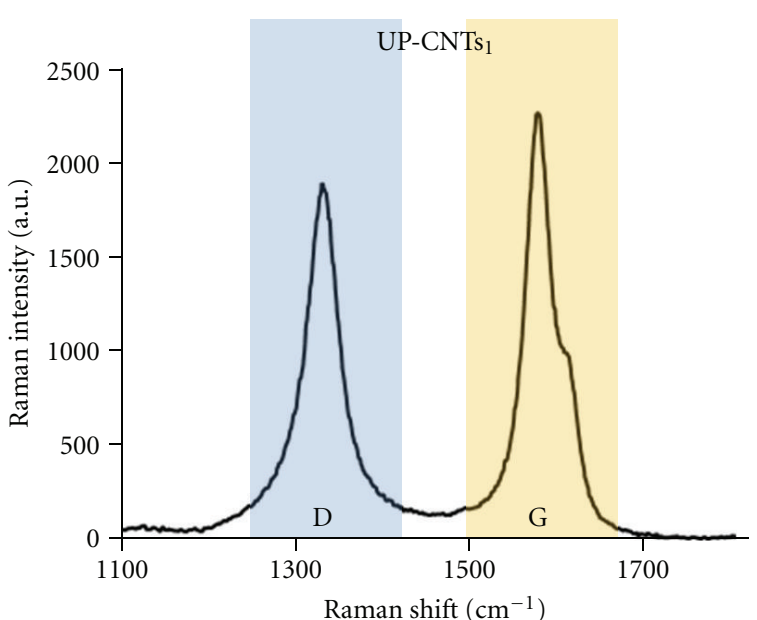

(a)

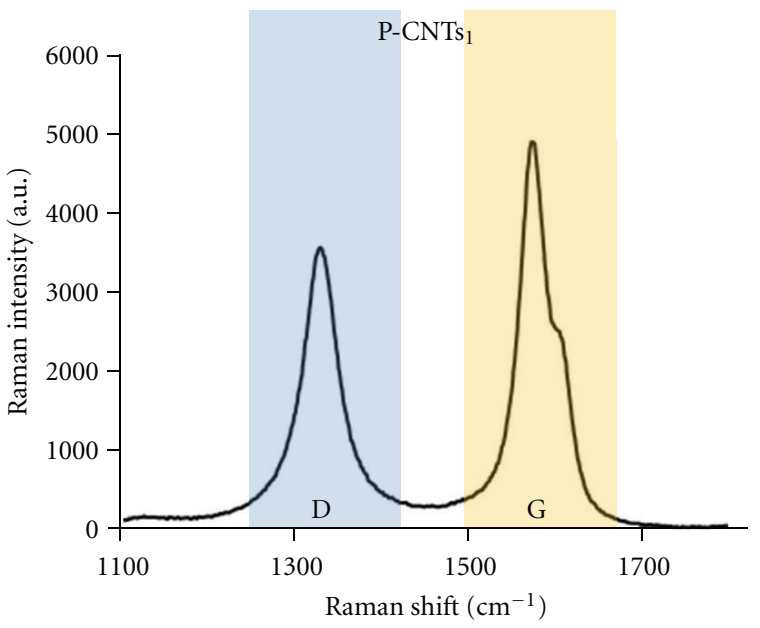

(c)

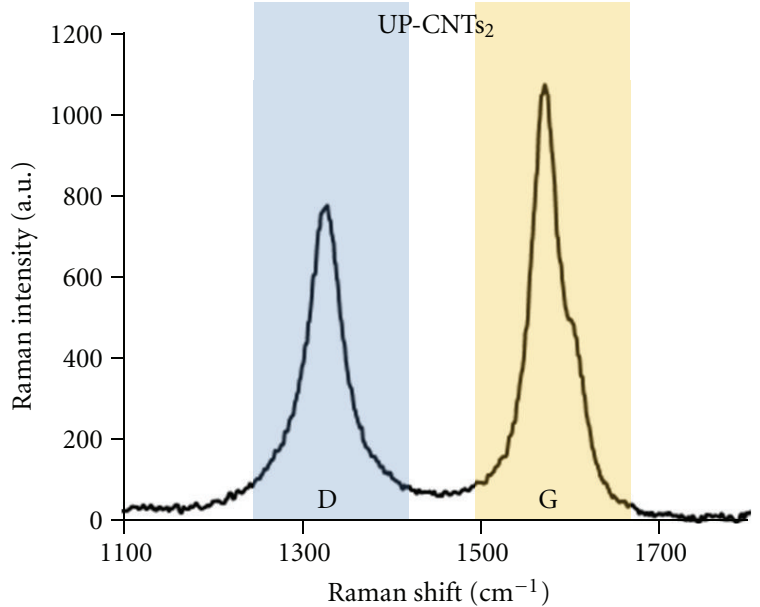

(b)

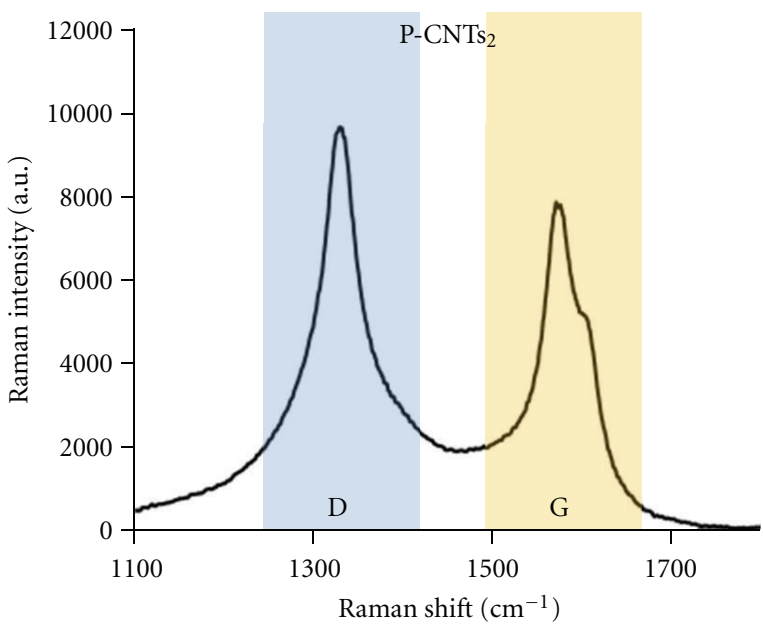

(d)

FIGURE 2: Raman spectra of CNTs samples. Different Raman spectra obtained from UP-CNTs $s_{1}$ (a), UP-CNTs 2 (b), P-CNTs 1 , (c) and P-CNTs (d). In each figure are shown the D-band at $1338 \mathrm{~cm}^{-1}$ and the G-band at $1600 \mathrm{~cm}^{-1}$ (laser excitation $632.8 \mathrm{~nm}$ ).

and corresponds to the tangential vibration of the carbon atoms, while the D-band is a typical sign for defective graphitic structures and is usually attributed to the presence of amorphous or disordered carbon in the CNTs samples. The comparison of the ratios of these two peaks intensities $\left(I_{G} / I_{D}\right)$ gives a measure of the quality of the samples. If bands have similar intensity this indicates a high quantity of structural defects $[25,26]$.

Based on the Raman spectra obtained for CNTs, it was observed that the UP-CNTs ${ }_{1}$ had a D-band intensity higher than that obtained for UP-CNTs 2 , and $I_{G} / I_{D}$ ratio obtained for UP-CNTs $s_{1}(1.19)$ was lower than ratio observed for UP$\mathrm{CNTs}_{2}$ (1.38). These data indicate that UP-CNTs 2 had better structural quality than UP-CNTs ${ }_{1}$. In the case of the P-CNTs, a lower D-band intensity was obtained for $\mathrm{P}_{-} \mathrm{CNTs}_{1}$; however $I_{G} / I_{D}$ ratio (1.37) was higher compared with ratio obtained for $\mathrm{P}-\mathrm{CNTs}_{2}\left(I_{G} / I_{D}\right.$ ratio $\left.=0.81\right)$. These results suggest that reflux purification process increases the structure quality of CNTs. These results agree with the observation that $\mathrm{P}_{-} \mathrm{CNTs}_{2}$ had more open-end formations than P-CNTs ${ }_{1}$.
3.2. Cell Viability of J774 MQ Cell Line. Viability results of MOs that interacted with UP-CNTs and P-CNTs at concentration of $0.06,0.6$ and $6 \mathrm{mg} / \mathrm{L}$ during $24 \mathrm{~h}$ are shown in Figures 3 and 4. MOs that interacted with UP-CNTs showed a significant decrease to $40 \%$ of cell viability independent of the dose of UP-CNTs 1 tested, as reported recently by our investigation group [27]. In MOs that interacted with UP-CNTs 2 a dose-dependent toxic effect was observed, no significant cytotoxic effect was observed at 0.06 and $0.6 \mathrm{mg} / \mathrm{L}$ concentration, whereas cells that interacted with $6 \mathrm{mg} / \mathrm{L}$ had a significant decrease in cellular viability, when compared to control (Figure 3). These results indicate that length and quality structure of the CNTs contributes to cellular toxicity. The toxic effect was greater with UP-CNT ${ }_{1}$ which were longer and more defectuous than UP-CNT 2 . These results agree with Yamashita et al. [28], who demonstrated that long and thick CNTs cause DNA damage and severe inflammatory effects. Similarly Sato et al. [29] observed that CNTs of $825 \mathrm{~nm}$ of length were more toxic than shorter CNTs. On the other hand, MOs that interacted with both groups of P-CNTs 


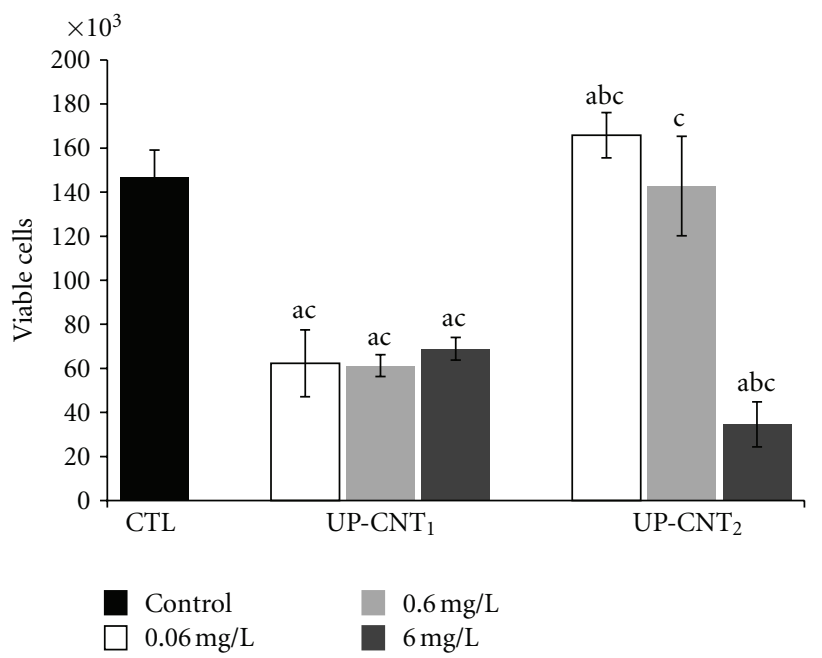

FIgURE 3: Viability of MOs that interacted with UP-CNTs at different concentration at $24 \mathrm{~h}$. Each bar represents mean \pm SD of two experiments done in triplicates $(n=6)$. a, $P<0.01$ denotes significant differences between mean values measured in the indicated group as compared to control without stimulus (CTL); b, $P<0.01$ denotes differences between mean values for CNTs at different concentration; $c, P<0.01$ denotes differences between mean values for a particular concentration among different CNTs.

had a dose-dependent toxic effect. However, cell viability had a significant decrease in MOs that interacted with P-CNTs ${ }_{1}$ at all concentration tested compared with control cultures (Figure 4). In the case of MOs that interacted with $\mathrm{P}_{-} \mathrm{CNTs}_{2}$, a significant decrease in cellular viability was detected only with $6 \mathrm{mg} / \mathrm{L}$, and lower concentrations had no significant effect (Figure 4).

Some authors have reported that CNTs interact with MTT and avoid salt metabolism, blocking formazan formation, a colored compound that is detected at $590 \mathrm{~nm}[30,31]$. In this study we incubated NP-CNTs and/or P-CNTS with MTT, and no interference or nonspecific reduction of MTT was detected (data not shown).

Several works have reported that the purification process eliminates residues present on the CNTs superface and that additionally introduces certain charged groups on their surface, allowing higher stability in aqueous solution and decreasing the toxic effect $[10,12]$. Nevertheless, the purification procedure could also contribute to CNT toxicity. Many studies have found that P-CNTs or acid-treated CNTs had greater toxic effect than UP-CNTs [31, 32]. Some authors attribute this behavior to the $\mathrm{COOH}$ groups, which may be causing a stress on cells $[10,12]$. On the contrary, works such as reported by Pulskamp et al. [30] showed that P-CNTs are less toxic than UP-CNT. These contradictory results could be related with the purification methodology used in those studies, since acid treatment modifies chemical and structural CNTs characteristics. Indeed, there are scarce cytoxicity studies in which purification and structural nanoparticle characteristics are considered and that is probably one reason why it has been hard to identify the origin of toxicity.

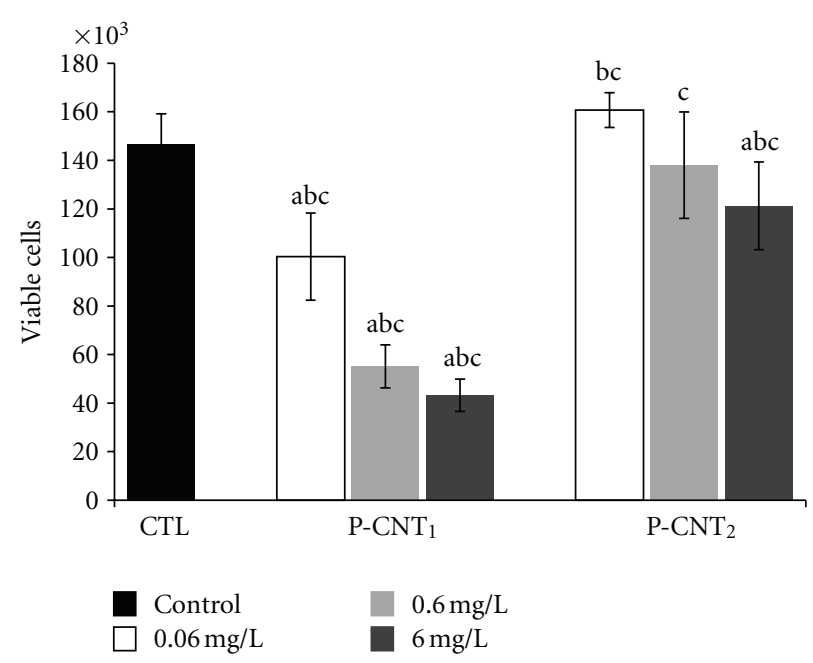

Figure 4: Viability of MOs that interacted with P-CNTs at different concentration at $24 \mathrm{~h}$. Each bar represents mean \pm SD of two experiments done in triplicates $(n=6)$. a, $P<0.01$ denotes significant differences between mean values measured in the indicated group as compared to control without stimulus (CTL); b, $P<0.01$ denotes differences between mean values for CNTs at different concentration; c, $P<0.01$ denotes differences between mean values for a particular concentration among different CNTs.

In our work, we found that the toxic effect of CNTs was dependent of length and $\mathrm{COOH}$ content. P-CNTs 2 whose length was $<1 \mu \mathrm{m}$ and $\mathrm{COOH}$ percentage was $7 \%$ were less toxic compared with $\mathrm{P}_{-\mathrm{CNT}} \mathrm{CN}_{1}$ (length $>100 \mu \mathrm{m}$ and $2.76 \%$ of $\mathrm{COOH})$. The relationship of $\mathrm{COOH}$ groups with the toxicity of CNTs on cellular cultures is not clear yet, since in most of the studies $\mathrm{COOH}$ groups are not quantified. However, the effect of $\mathrm{O}$ content has been reported in some toxicity studies, where a greater toxicity of P-CNTs was found with low content of $\mathrm{O}[27,30]$, and P-CNTs with $\mathrm{O}$ content above $20 \%$ decreased notably the cytotoxicity $[31,33]$. Considering that the $\mathrm{O}$ content is associated with the $\mathrm{COOH}$ groups in the P-CNTs, our results agree with those in which P-CNTs have high $\mathrm{O}$ content. However the $\mathrm{COOH}$ quantification is desirable to make a direct toxicity comparison.

In addition to chemical and structural properties, the aggregation differences between CNTs could be related with cytotoxicity variations [33-35]. In our study, treatment with $3: 1 \mathrm{H}_{2} \mathrm{SO}_{4} / \mathrm{HNO}_{3}$ and sonication for $48 \mathrm{~h}$ allowed to obtain CNTs shorter and with a higher content of $\mathrm{COOH}$ groups, which were more soluble in aqueous medium. Moreover, increase of $\mathrm{COOH}$ groups in the surface of the CNTs is indispensable to favour nanoparticle functionalization with drugs or peptides, a relevant process for nanocarriers or nanovaccines production.

\section{Conclusion}

Results obtained in this work demonstrated that purification methodology is a key event for P-CNTs production for their use in nanobiotechnology; acid treatment with $3: 1$ $\mathrm{H}_{2} \mathrm{SO}_{4} / \mathrm{HNO}_{3}$ and sonication was highly effective to remove 
Fe and permits us to obtain P-CNTs with low cytotoxicity on MOs of J774A cell line. Cytotoxic effect was related to the length and $\mathrm{COOH}$ content of P-CNTs. This finding is of great importance for generation of nanobiotechnological products such as nanocarriers or nanovaccines, in which CNTs exhibit minimal toxicity and high expectations in the future.

\section{Acknowledgments}

This work was partially supported by FOMIX-ChihuahuaCONACyT (CHIH-2008-C01-92074). S. L. Montes-Fonseca was the recipient of a Ph.D. scholarship from CONACyT (reg. 213778). The authors have no other relevant affiliations or financial involvement with any organization or entity with a financial interest in or financial conflict with the subject matter or materials discussed in the paper apart from those disclosed.

\section{References}

[1] N. Tagmatarchis and M. Prato, "Carbon-based materials: from fullerene nanostructures to functionalized carbon nanotubes," Pure and Applied Chemistry, vol. 77, no. 10, pp. 1675-1684, 2005.

[2] X. Zhao and R. Liu, "Recent progress and perspectives on the toxicity of carbon nanotubes at organism, organ, cell, and biomacromolecule levels," Environment International, vol. 40, no. 1, pp. 244-255, 2012.

[3] R. Singh, D. Pantarotto, L. Lacerda et al., "Tissue biodistribution and blood clearance rates of intravenously administered carbon nanotube radiotracers," Proceedings of the National Academy of Sciences of the United States of America, vol. 103, no. 9, pp. 3357-3362, 2006.

[4] S. S. Wong, E. Joselevich, A. T. Woolley, C. L. Cheung, and C. M. Lieber, "Covalently functionalized nanotubes as nanometresized probes in chemistry and biology," Nature, vol. 394, no. 6688 , pp. 52-55, 1998.

[5] A. Hirsch, "Functionalization of single-walled carbon nanotubes," Angewandte Chemie - International Edition, vol. 41, no. 11, pp. 1853-1859, 2002.

[6] S. E. McNeil, "Nanotechnology for the biologist," Journal of Leukocyte Biology, vol. 78, no. 3, pp. 585-594, 2005.

[7] T. Fifis, A. Gamvrellis, B. Crimeen-Irwin et al., "Sizedependent immunogenicity: therapeutic and protective properties of nano-vaccines against tumors," Journal of Immunology, vol. 173, no. 5, pp. 3148-3154, 2004.

[8] D. Pantarotto, C. D. Partidos, R. Graff et al., "Synthesis, structural characterization, and immunological properties of carbon nanotubes functionalized with peptides," Journal of the American Chemical Society, vol. 125, no. 20, pp. 6160-6164, 2003.

[9] V. L. Colvin, "The potential environmental impact of engineered nanomaterials," Nature Biotechnology, vol. 21, no. 10, pp. 1166-1170, 2003.

[10] A. Magrez, S. Kasas, V. Salicio et al., "Cellular toxicity of carbon-based nanomaterials," Nano Letters, vol. 6, no. 6, pp. 1121-1125, 2006.

[11] L. Ding, J. Stilwell, T. Zhang et al., "Molecular characterization of the cytotoxic mechanism of multiwall carbon nanotubes and nano-onions on human skin fibroblast," Nano Letters, vol. 5, no. 12, pp. 2448-2464, 2005.
[12] M. Bottini, S. Bruckner, K. Nika et al., "Multi-walled carbon nanotubes induce T lymphocyte apoptosis," Toxicology Letters, vol. 160, no. 2, pp. 121-126, 2006.

[13] Y. Y. Guo, J. Zhang, Y. F. Zheng, J. Yang, and X. Q. Zhu, "Cytotoxic and genotoxic effects of multi-wall carbon nanotubes on human umbilical vein endothelial cells in vitro," Mutation Research - Genetic Toxicology and Environmental Mutagenesis, vol. 721, no. 2, pp. 184-191, 2011.

[14] N. A. Monteiro-Riviere, R. J. Nemanich, A. O. Inman, Y. Y. Wang, and J. E. Riviere, "Multi-walled carbon nanotube interactions with human epidermal keratinocytes," Toxicology Letters, vol. 155, no. 3, pp. 377-384, 2005.

[15] C. Cheng, K. H. Müller, K. K. K. Koziol et al., "Toxicity and imaging of multi-walled carbon nanotubes in human macrophage cells," Biomaterials, vol. 30, no. 25, pp. 4152-4160, 2009.

[16] M. L. Di Giorgio, S. D. Bucchianico, A. M. Ragnelli, P. Aimola, S. Santucci, and A. Poma, "Effects of single and multi walled carbon nanotubes on macrophages: cyto and genotoxicity and electron microscopy," Mutation Research - Genetic Toxicology and Environmental Mutagenesis, vol. 722, no. 1, pp. 20-31, 2011.

[17] G. V. Letsou, J. H. Connelly, R. M. Delgado et al., "Is native aortic valve commissural fusion in patients with longterm left ventricular assist devices associated with clinically important aortic insufficiency?" Journal of Heart and Lung Transplantation, vol. 25, no. 4, pp. 395-399, 2006.

[18] C. A. Poland, R. Duffin, I. Kinloch et al., "Carbon nanotubes introduced into the abdominal cavity of mice show asbestoslike pathogenicity in a pilot study," Nature Nanotechnology, vol. 3, no. 7, pp. 423-428, 2008.

[19] T. Saito, K. Matsushige, and K. Tanaka, "Chemical treatment and modification of multi-walled carbon nanotubes," Physica B, vol. 323, no. 1-4, pp. 280-283, 2002.

[20] A. Aguilar-Elguézabal, W. Antúnez, G. Alonso, F. P. Delgado, F. Espinosa, and M. Miki-Yoshida, "Study of carbon nanotubes synthesis by spray pyrolysis and model of growth," Diamond and Related Materials, vol. 15, no. 9, pp. 1329-1335, 2006.

[21] H. Hu, P. Bhowmik, B. Zhao, M. A. Hamon, M. E. Itkis, and R. C. Haddon, "Determination of the acidic sites of purified single-walled carbon nanotubes by acid-base titration," Chemical Physics Letters, vol. 345, no. 1-2, pp. 25-28, 2001.

[22] T. Mosmann, "Rapid colorimetric assay for cellular growth and survival: application to proliferation and cytotoxicity assays," Journal of Immunological Methods, vol. 65, no. 1-2, pp. 55-63, 1983.

[23] C. Cheng, K. H. Müller, K. K. K. Koziol et al., "Toxicity and imaging of multi-walled carbon nanotubes in human macrophage cells," Biomaterials, vol. 30, no. 25, pp. 4152-4160, 2009.

[24] J. Zhang, H. Zou, Q. Qing et al., "Effect of chemical oxidation on the structure of single-walled carbon nanotubes," Journal of Physical Chemistry B, vol. 107, no. 16, pp. 3712-3718, 2003.

[25] A. M. Keszler, L. Nemes, S. R. Ahmad, and X. Fang, "Characterisation of carbon nanotube materials by Raman spectroscopy and microscopy - A case study of multiwalled and singlewalled samples," Journal of Optoelectronics and Advanced Materials, vol. 6, no. 4, pp. 1269-1274, 2004.

[26] V. Datsyuk, M. Kalyva, K. Papagelis et al., "Chemical oxidation of multiwalled carbon nanotubes," Carbon, vol. 46, no. 6, pp. 833-840, 2008.

[27] S. L. Montes-Fonseca, E. Orrantia-Borunda, A. AguilarElguezabal, C. G. Horta, P. Talamás-Rohana, and B. SánchezRamirez, "Cytotoxicity of functionalized carbon nanotubes in J774A macrophages," Nanomedicine: Nanotechnology, Biology and Medicine. In press. 
[28] K. Yamashita, Y. Yoshioka, K. Higashisaka et al., "Carbon nanotubes elicit DNA damage and inflammatory response relative to their size and shape," Inflammation, vol. 33, no. 4, pp. 276-280, 2010.

[29] Y. Sato, A. Yokoyama, K. I. Shibata et al., "Influence of length on cytotoxicity of multi-walled carbon nanotubes against human acute monocytic leukemia cell line THP-1 in vitro and subcutaneous tissue of rats in vivo," Molecular BioSystems, vol. 1, no. 2, pp. 176-182, 2005.

[30] K. Pulskamp, S. Diabaté, and H. F. Krug, "Carbon nanotubes show no sign of acute toxicity but induce intracellular reactive oxygen species in dependence on contaminants," Toxicology Letters, vol. 168, no. 1, pp. 58-74, 2007.

[31] T. Coccini, E. Roda, D. A. Sarigiannis et al., "Effects of watersoluble functionalized multi-walled carbon nanotubes examined by different cytotoxicity methods in human astrocyte D384 and lung A549 cells," Toxicology, vol. 269, no. 1, pp. 41$53,2010$.

[32] O. Vittorio, V. Raffa, and A. Cuschieri, "Influence of purity and surface oxidation on cytotoxicity of multiwalled carbon nanotubes with human neuroblastoma cells," Nanomedicine: Nanotechnology, Biology, and Medicine, vol. 5, no. 4, pp. 424-431, 2009.

[33] D. M. Brown, I. A. Kinloch, U. Bangert et al., "An in vitro study of the potential of carbon nanotubes and nanofibres to induce inflammatory mediators and frustrated phagocytosis," Carbon, vol. 45, no. 9, pp. 1743-1756, 2007.

[34] P. M. V. Raja, J. Connolley, G. P. Ganesan et al., "Impact of carbon nanotube exposure, dosage and aggregation on smooth muscle cells," Toxicology Letters, vol. 169, no. 1, pp. 51-63, 2007.

[35] P. Wick, P. Manser, L. K. Limbach et al., "The degree and kind of agglomeration affect carbon nanotube cytotoxicity," Toxicology Letters, vol. 168, no. 2, pp. 121-131, 2007. 

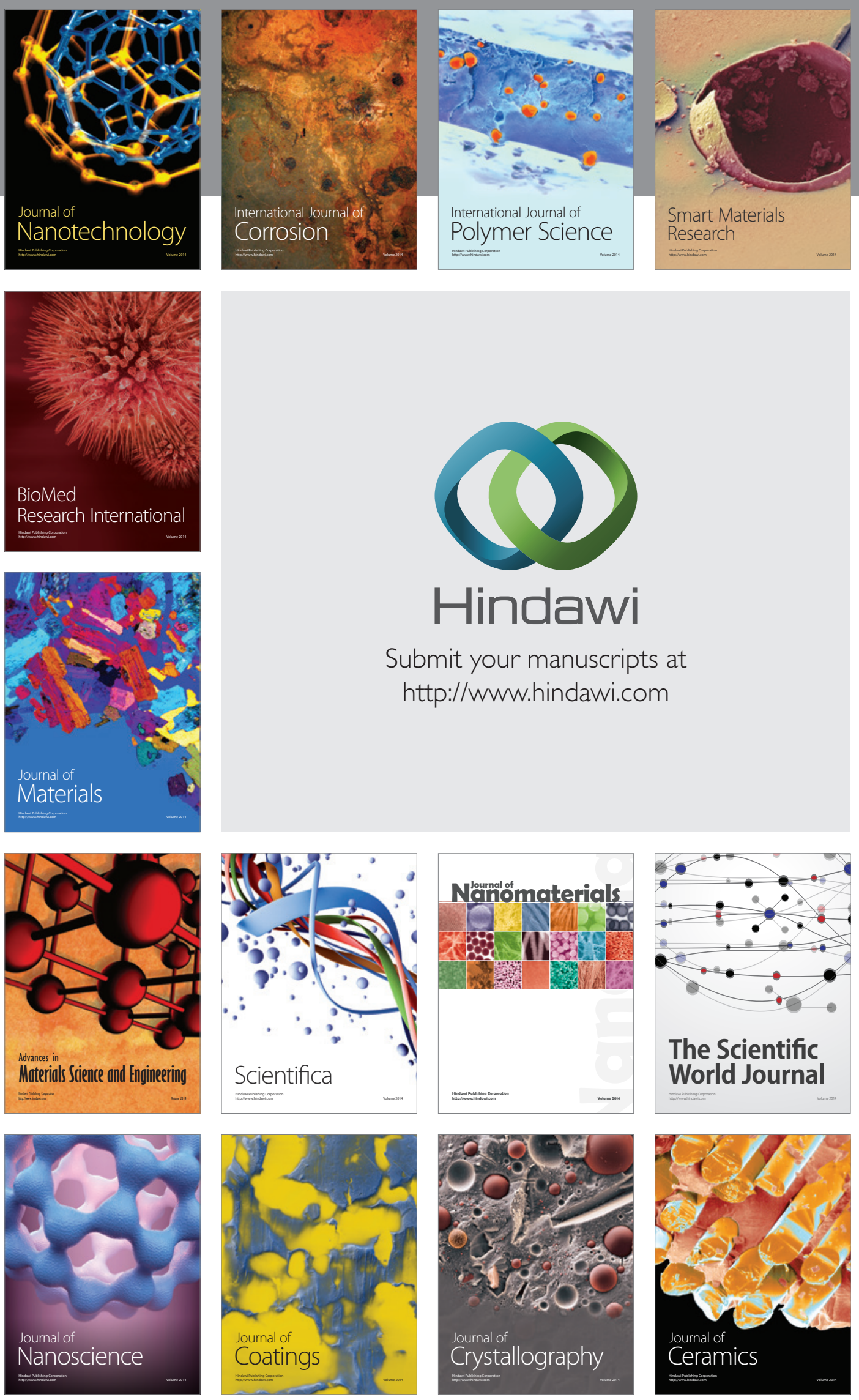

The Scientific World Journal

Submit your manuscripts at

http://www.hindawi.com

\section{World Journal}

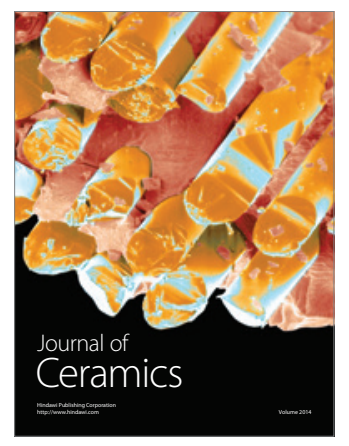

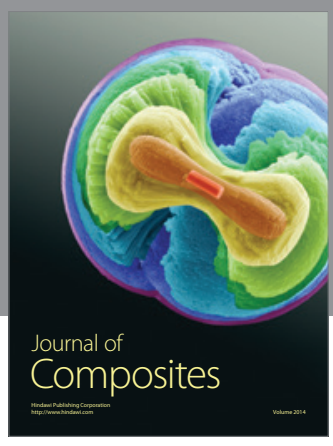
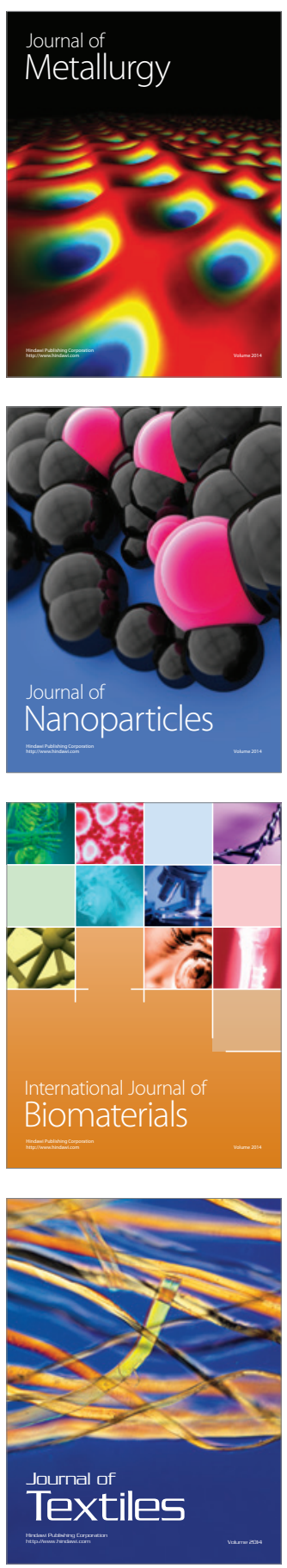